\title{
Sulphur corrosion effect on the electrical performance of silver films elaborated by physical vapor deposition.
}

\author{
P. Perrenot ${ }^{(1)}$, S. Pairis ${ }^{(2,3)}$, D. Bourgault ${ }^{(2,3)}$, N. Caillault ${ }^{(1) *}$ \\ (1) Schneider-Electric France, 38TEC/T1, 37 quai Paul Louis Merlin, 38050 Grenoble \\ Cedex 9, France \\ ${ }^{(2)}$ Univ. Grenoble Alpes, Institut Néel, F-38042 Grenoble, France. \\ (3) Centre National de la Recherche Scientifique / Institut Néel, 25 Avenue des Martyrs, \\ BP 166, 38042 Grenoble Cedex 9, France \\ * Corresponding author ; E-mail : nathalie.caillault@schneider-electric.com ;
}

\begin{abstract}
Electrical properties of Ag films elaborated by Physical Vapor Deposition (PVD) process has been studied before and after corrosion exposure.

We have shown that the minimum thickness of silver to resist to sulphurization atmosphere is one micron with an adherent coating. After a sulfurization time of $600 \mathrm{~min}$, an electrical resistivity increase of only $10 \%$ is obtained for a film with 2 microns in thickness. This value is about $20 \%$ higher than the electrical resistivity of pure silver bulk material.

For industrial applications of silver coatings, these results are relevant and demonstrate that PVD is an interesting process compared to the electrochemical ones for which silver thicknesses close to 5 microns are necessarily coated.
\end{abstract}

\section{Keywords:}

Ag2S, Thin Films, DC magnetron sputtering, Electrical Conductivity, Corrosion 


\section{Introduction}

Silver coatings are widely used as contact material on conductive bars in lot of power supply companies because of their electrical properties. Silver combines low electrical and thermal conductivities with good corrosion resistance [1].

Several studies have been done on silver and copper corrosion and revealed that silver sulfide is the main corrosion product obtained when the silver is exposed to indoor and outdoor environments [2-9]. This corrosion film induces an insulating layer at the contact surfaces causing electrical failures on the devices. Up to now, electrochemical ways offer the best compromise between materials performance and process costs to realise silver coatings on conductive parts for industrial products. However to deposit silver coating on non-conductive parts, this process cannot be directly used and an under-layer must be applied. PVD (Physical Vapor Deposition) process is a green process is an alternative process to deposit silver coatings on any type of support, substrate. Magnetron sputtering is one of the processes currently used for depositing coatings with high corrosion resistance [10-14].

The time life of industrial conductive bars is between 20 and 30 years. Furthermore, products must resist to different corrosion atmosphere depending of country. According to this point, power supplier companies recommend to deposit electrochemically on conductive copper bars a thickness between 2 and $5 \mu \mathrm{m}$ of silver layers.

The useful thickness of the Ag layer allowing good corrosion resistance is not yet well determined. In this context, this paper aims at understanding the impact of Ag thickness deposited using a PVD process on electrical conductivity properties and on corrosion strength.

\section{Experiments}

Silver films are deposited using a dc magnetron sputtering device. $50 \mathrm{~mm}$ diameter hot pressed targets of pure silver were used. The substrates used were glass, in order to measure electrical resistivity properties. The chamber pressure before deposition was lower than $510^{-7}$ mbar. Influence of sputtering parameters such as argon pressure (4.5 and $8 \mu \mathrm{bar}$ ) and deposition time (between $200 \mathrm{~s}$ and 1375 s) on transport properties and corrosion strength was 
studied. Plasma power and substrate-target distance are fixed respectively at $75 \mathrm{~W}$ and 7.5 cm. Glass substrates were cleaned with alcohol in ultra sound bath before use. Before Ag deposition, substrate etching was realized during 5 min at 30W.

Film thickness was measured with Dektak apparatus. Because the electrical resistivity calculation is very sensitive to the thickness measurement, a thickness calibration has been realized in this study. For this, films have been deposited under two Ar pressures (4.5 and 8 $\mu \mathrm{bar})$ at $75 \mathrm{~W}$ and with deposition times allowing a thickness higher than $1000 \mathrm{~nm}$. For all the Ag films deposited, three thickness measurements are realized at different spots to obtain a mean and a standard deviation.

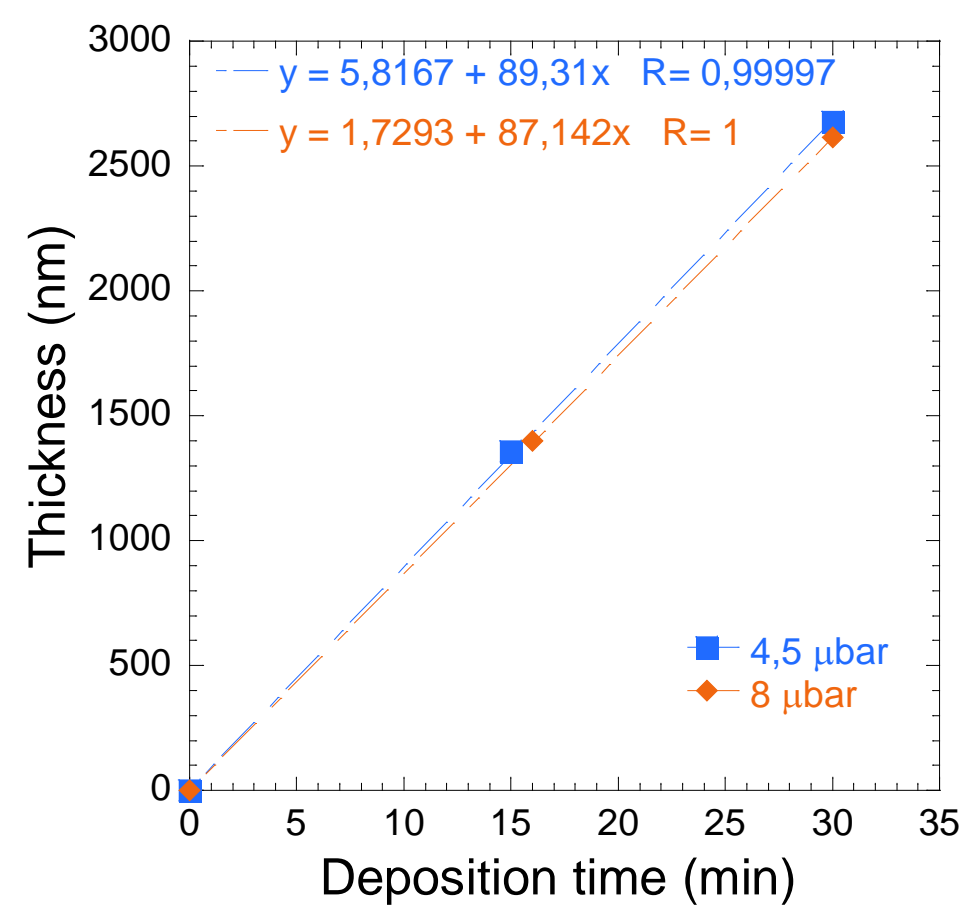

Figure 1 : Thickness versus deposition time for a argon pressure of 4,5 and $8 \mu \mathrm{bar}$.

The linear fits obtained for both Ar pressures are used to determine film thicknesses for very short time depositions (Figure 1).

The crystalline structure, surface microstructure morphology and composition of films after sulfurization were investigated with an X-Ray Diffraction (XRD) system (D5000 Brucker) in the conventional $\Theta-2 \Theta$ mode using the $\mathrm{Cu} \mathrm{K} \alpha$ and an environmental scanning electron microscope (ESEM FEI Quanta 200) equipped with a Bruker EDX system.

For film composition analysis, at least three different regions were probed with the same conditions (accelerating voltage, beam current, magnification, acquisition time). Quantitative 
analysis of the different elements (atomic percent concentration) was performed by nonstandard analysis (using ZAF correction procedures) with a $\pm 1 \%$ accuracy.

Electrical resistivity was measured at room temperature using the standard four-point collinear probe method. The universal Jandel four linear points test equipment associated to a Keithley 6221 DC power source and a Keithley 2000 multimeter yielded electrical resistance measurements. Electrical resistivity is then calculated using equation 1. For the calculation, the $\mathrm{K}$ factor which is function of the electrode arrangement geometry is introduced. Related to studied coatings, we assume that with a standard deviation between $210^{-4}$ to $610^{-4} \mu \Omega \cdot \mathrm{m}$, the measure is acceptable.

Equation (1) $\rho(\boldsymbol{\Omega} \Omega \cdot \mathbf{m})=\mathbf{K}^{*} \mathbf{R}^{*} \mathbf{e}^{*} \mathbf{1 0} \mathbf{0}^{-3}=\mathbf{K}^{*}(\mathrm{U} / \mathrm{I}) * \mathbf{e}^{*} \mathbf{1 0} \mathbf{0}^{-3}$

$\rho$ resistivity $\mu \Omega \cdot m$, e : thickness in $\mathrm{nm}, \quad \mathrm{R}$ : resistance in ohm, $\mathrm{K}$ : factor for thin layers $(\mathrm{K}=4.532) \quad \mathrm{U}$ : voltage in $\mathrm{mV}, \quad \mathrm{I}$ : current in $\mathrm{mA}$

When silver is submitted to sulfurized compounds such as $\mathrm{SO}_{2}$ and $\mathrm{H}_{2} \mathrm{~S}$, a corrosion at the surface occurs and electrical conductivity can be modified. The test used in this paper, consists in applying solution of $0.1 \%$ ammonium sulfide on Ag layer. Films are half immersed in the ammonium sulfide solution for a given time, then rinsed thoroughly with distilled water and finally dried in dry air. After this protocol, electrical resistivity is measured.

\begin{tabular}{|c|c|c|c|c|c|c|}
\hline & Ag1 & Ag2 & Ag3 & Ag4 & Ag5 & Ag6 \\
\hline $\begin{array}{c}\text { Deposition } \\
\text { pressure }(\mu \mathrm{bar})\end{array}$ & 4.5 & 4.5 & 8 & 8 & 8 & 8 \\
\hline Deposition time (s) & 333 & 666 & 342 & 690 & 1374 & 204 \\
\hline $\begin{array}{c}\text { Thickness }(\mu \mathrm{m}) \\
\begin{array}{c}\text { Electrical } \\
\text { resistivity }(\mu \Omega \mathrm{m})\end{array}\end{array}$ & 0.5 & 1 & 0.5 & 1 & 2 & 0.3 \\
\hline
\end{tabular}

Table 1 : Sputtering conditions for Ag films deposited under $75 \mathrm{~W}$ and with substrate-target distance of $7.5 \mathrm{~cm}$ and electrical resistivity before sulfurization. 


\section{Results and discussion}

Table 1 shows the sputtering conditions of the different Ag films obtained and the corresponding thickness.

As shown in table 1, the electrical resistivity of samples deposited under different conditions is between 0.018 and $0.020 \mu \Omega$.m [15]. These results show that the resistivity of silver layers is from $15 \%$ to $28 \%$ higher than raw silver resistivity $(0.0157 \mu \Omega . m)$. With these measurements, no influence of thickness and pressure seems to appear on electrical resistivity.

Films deposited have then been immersed in the ammonium sulfide solution during various times. After rinsing and drying, electrical properties are measured again. On the pictures (Figure 2), silver coloration appears at $\mathrm{t}=7 \mathrm{~min}$ and delamination of coating is observed at $\mathrm{t}=$ $30 \mathrm{~min}$ for $300 \mathrm{~nm}$ silver layer.
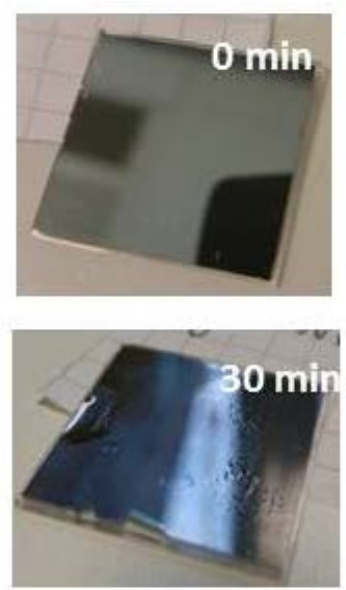
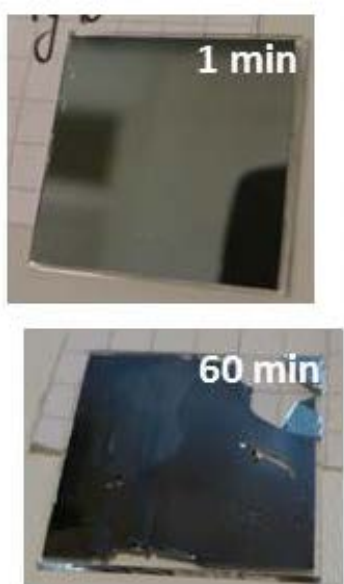
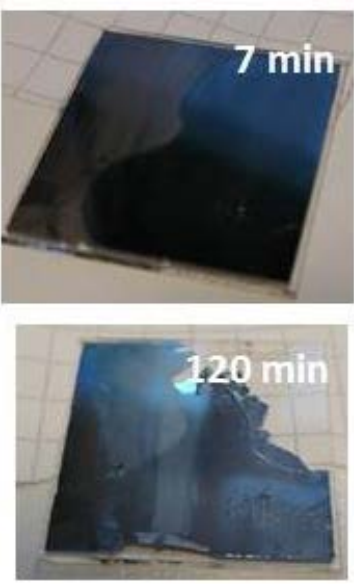

Figure 2: Pictures of a $300 \mathrm{~nm}$ Ag coatings(Ag6) for different sulfurization times. The glass substrate is $25 * 25 \mathrm{~mm}^{2}$

Figure 3 shows the X-ray diffraction patterns of Ag films deposited under different conditions after sulfurization time of $120 \mathrm{~min}$. 


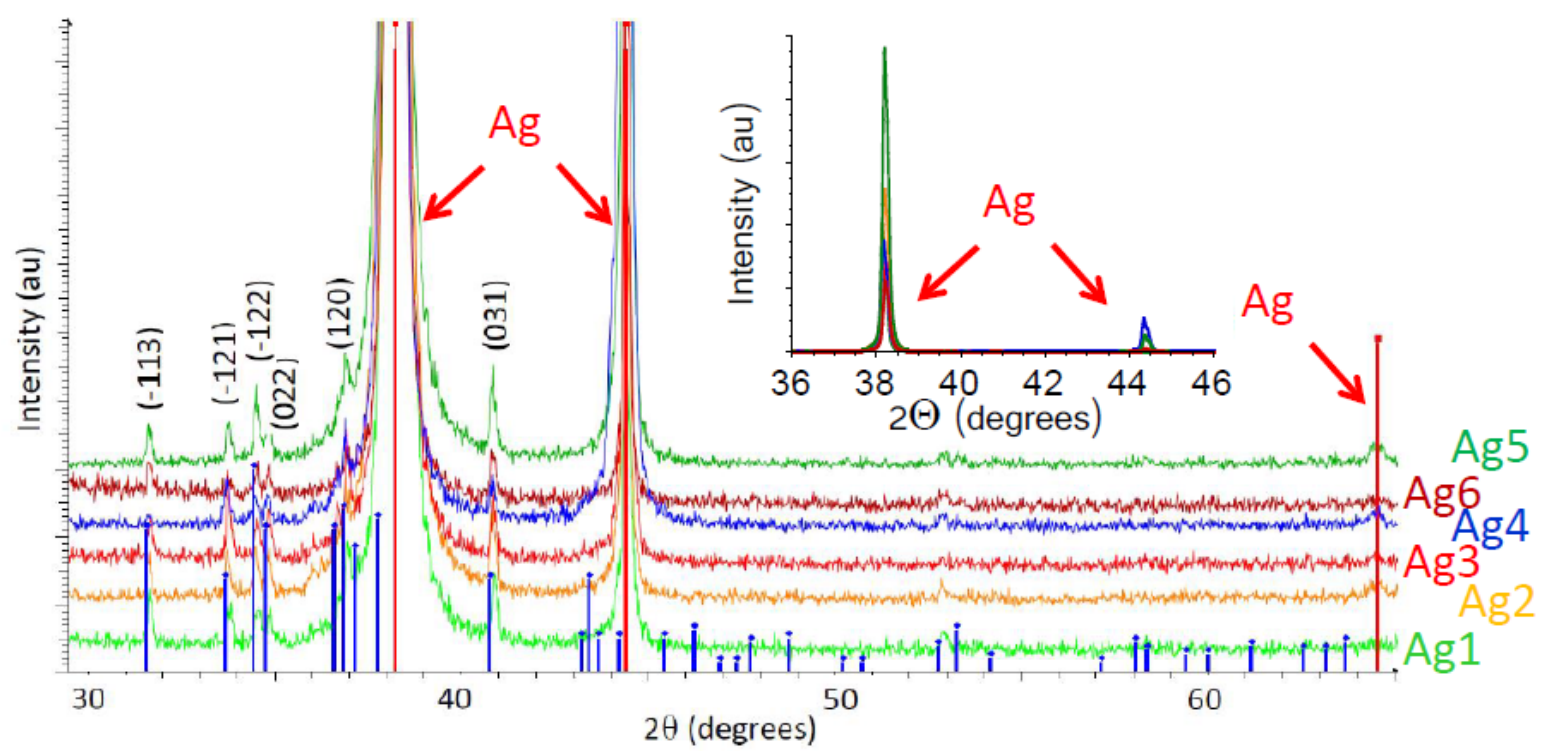

Figure 3: X-ray diffraction patterns of Ag films deposited under different conditions after a sulfurization time of 120 min. Peaks of the Ag (in red, JCPDS Card File: 00-087-0718) and $\alpha$ $\mathrm{Ag}_{2} \mathrm{~S}$ (acanthite) (in blue, JCPDS Card File: 00-014-0072) are marked.

The diffraction patterns were indexed to the $\mathrm{Ag}$ and monoclinic $\mathrm{Ag}_{2} \mathrm{~S}$ phases. This last is in good agreement with the reported data for $\alpha-\mathrm{Ag}_{2} \mathrm{~S}$ (acanthite) (JCPDS Card File: 00-0140072).

In inset are shown X-ray diffraction patterns at full scale. Ag peak intensities recorded for the sulfurized films reveal that only a small fraction of Ag is transformed into Ag2S phase(from $18 \%$ up to $45 \%$ ). Despite the delamination observed, probably due to the low adhesion of silver to the glass substrate, films present a good strength to the sulfurization after $120 \mathrm{~min}$ exposure. This is confirmed by the SEM images and EDX compositions described below.

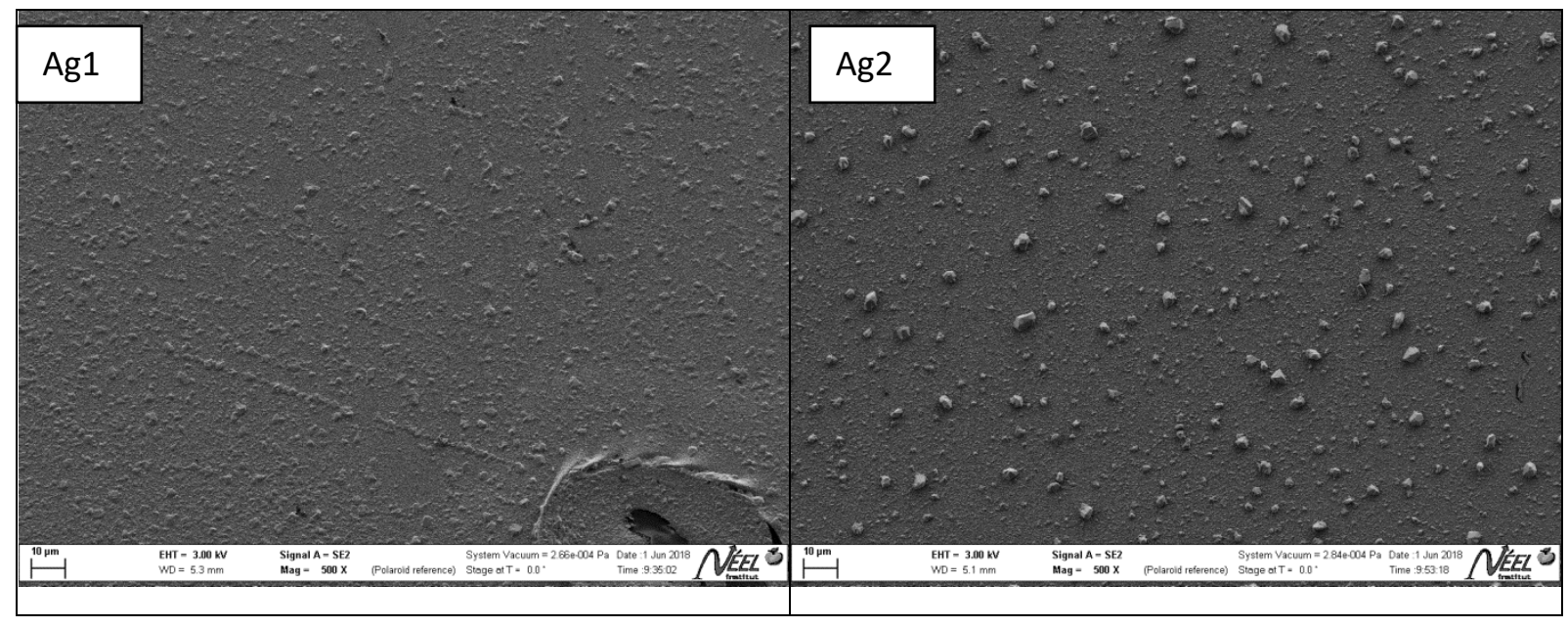




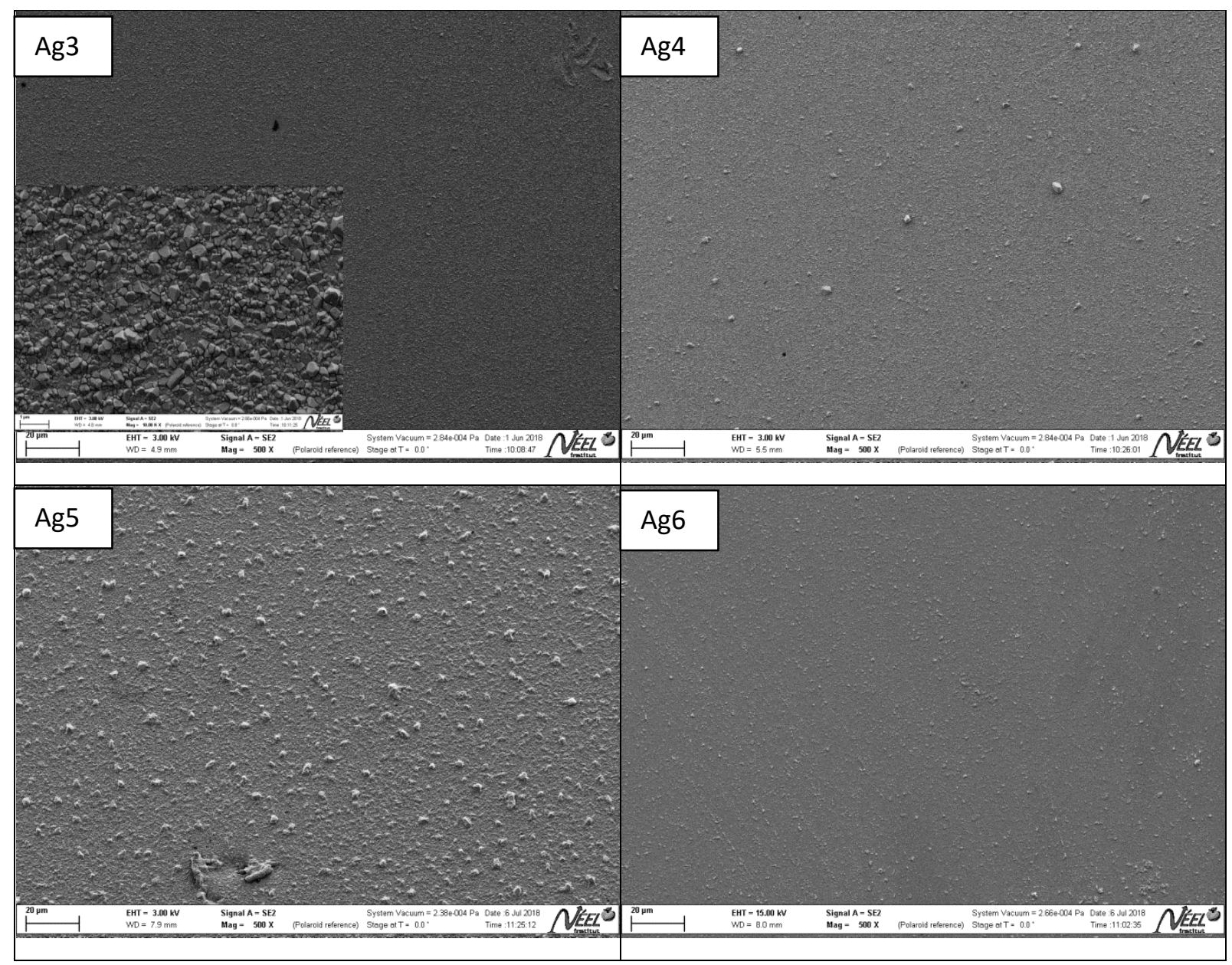

Figure 4 : SEM images of the Ag1-Ag6 films prepared under different conditions process.

Inset in Ag3 picture shows a x10000 magnification for grain size observation.

Figure 4 shows x500 SEM images of the films prepared under different conditions process. The microstructures are similar for the 6 samples, with a matrix of homogeneous grains having 200nm in diameter (see inset in Ag3 film). For film with thickness higher than $1 \mu \mathrm{m}$ (Ag2, Ag4 and Ag5), localized nuggets appears inside the matrix.

Table 2 shows the evolution of the atomic percentage of the silver and sulphur elements for sulfurized films. Compositions for matrix, nugget and mean values are given.

\begin{tabular}{|c|c|c|c|}
\hline \multirow{2}{*}{} & \multicolumn{3}{|c|}{ Atomic composition } \\
& \multicolumn{3}{c|}{ S/Ag (at\%) $\pm 1 \%$} \\
\hline & Matrix & Nugget & Mean \\
\hline Ag1 & $7 / 93$ & $28 / 72$ & $11 / 89$ \\
\hline Ag2 & $10 / 90$ & $15 / 85$ & $6 / 94$ \\
\hline
\end{tabular}




\begin{tabular}{|c|c|c|c|}
\hline Ag3 & $15 / 85$ & - & $15 / 85$ \\
\hline Ag4 & $11 / 89$ & - & $11 / 89$ \\
\hline Ag5 & $11 / 89$ & $27 / 73$ & $10 / 90$ \\
\hline Ag6 & $5 / 95$ & $19 / 81$ & $7 / 93$ \\
\hline
\end{tabular}

Table 2 : Sulphur and silver compositions for the different films after 600 min of sulfurization. Compositions for matrix, nugget and mean values are given.

For all films, the average S/Ag ratio is lower than 0.33, indicating that a large part of Ag was not converted into $\mathrm{Ag}_{2} \mathrm{~S}$ confirming the $\mathrm{X}$ ray analysis described before.

It is difficult to observe a tendency for different thicknesses or pressure deposition. Indeed, the mean value compositions are very similar for the different sulfurized films with a composition varying between $\mathrm{Ag}_{93} \mathrm{~S}_{7}$ and $\mathrm{Ag}_{85} \mathrm{~S}_{15}$. However, for film showing nuggets, the matrix composition is lower in sulphur but nuggets present a composition rich in sulphur. It should be noticed that such nuggets is very sensitive to the electron beam heating during observation leading to the $\alpha-\mathrm{Ag}_{2} \mathrm{~S}$ (acanthite) $-\beta-\mathrm{Ag}_{2} \mathrm{~S}$ (argentite) phase transformation as observed by Sadovnikov et al. [16].

According the SEM and EDX analysis, it seems that the growth of these sulphur-rich nuggets occurs for films thicker than microns. The influence of the sulfurization time on the electrical conductivity properties is now presented.

Figure 5 shows an increase of electrical resistivity with sulfurization time $[17,18,19]$ due to the formation of Ag2S phase having an electrical resistivity $10^{6}$ times higher than that of the Ag phase. The largest increase is obtained when layers have 0.3 and $0.5 \mu \mathrm{m}$ thickness. After 10 min of sulfurization there is $20 \%$ of increase. With a deposition pressure of $8 \mu \mathrm{bar}$, electrical resistivity is lower than values obtained at $4.5 \mu$ bar when thickness coating is over 1 $\mu \mathrm{m}$. 


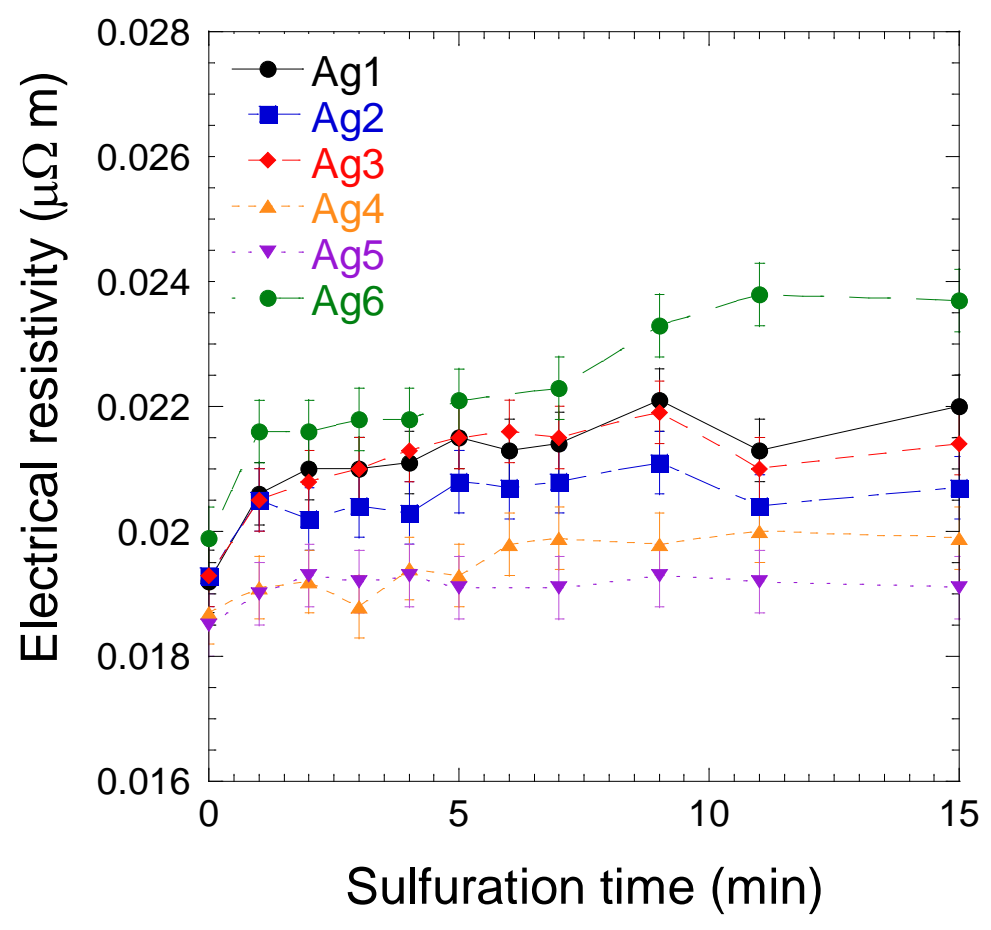

Figure 5: Electrical resistivity versus sulfurization time for Ag films deposited under different conditions (Ag1-Ag6).

For longer time of corrosion, the electrical resistance increase is less important for thicker films (see figure 6). Some coatings have taken off, at time between $240 \mathrm{~min}$ and $600 \mathrm{~min}$ of sulfurization : The thinner $(0.3 \mu \mathrm{m})$ but also the thicker $(2 \mu \mathrm{m})$ which have been made at 8 ubar. For $1 \mu \mathrm{m}$ samples (at 4.5 and $8 \mu \mathrm{bar}$ ), electrical resistivity increase remain low with only $10 \%$ for Ag2, and $20 \%$ for sample Ag4 after a sulfurization time of $600 \mathrm{~min}$. For both samples, the electrical resistivity remains lower than $0.022 \mu \Omega . m$. 


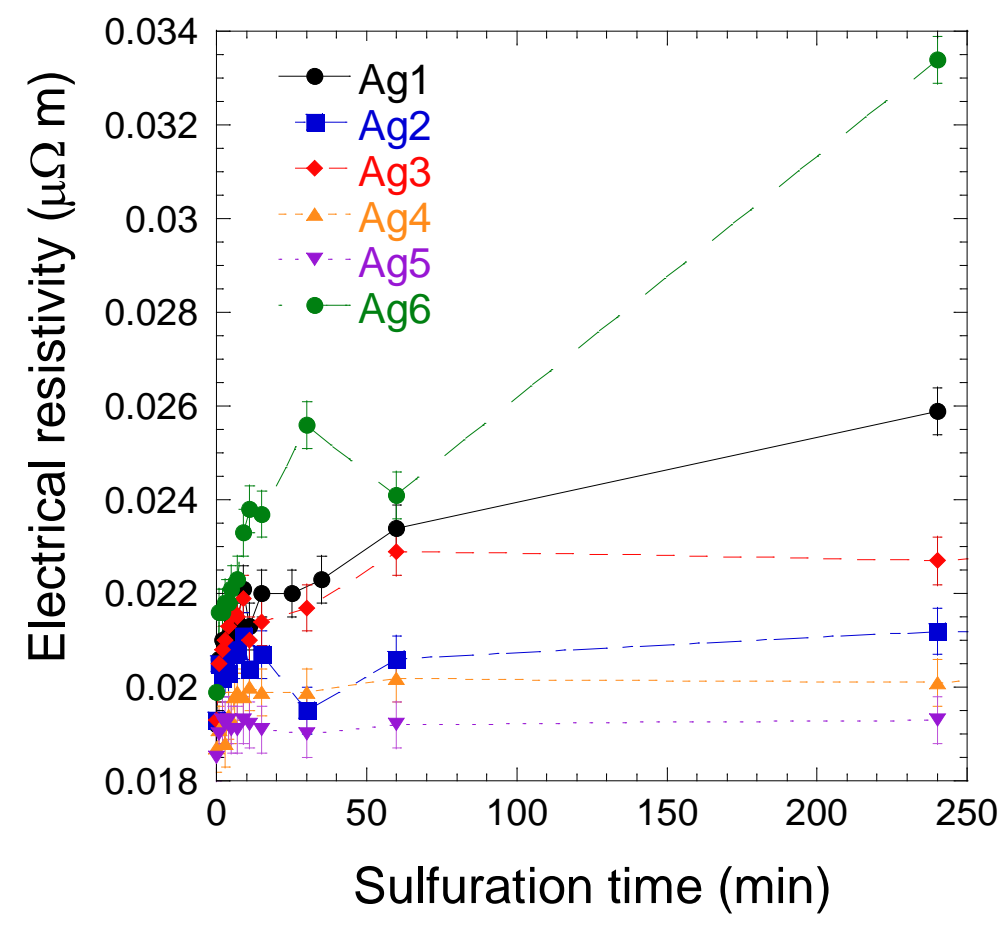

Figure 6: Long sulfurization time dependence of the electrical resistivity for Ag films deposited under different conditions (Ag1-Ag6).

Influence of silver layer thickness on the corrosion strength is represented figure 7 . This confirms that layers of silver coating over $1 \mu \mathrm{m}$, maintain their electrical performance under sulfurization. According to the SEM images and the EDX analysis, sulfurization resistance is better for films with high thickness showing nuggets on the surface. Nuggets growth seems to preserve the sulfurization of the silver films and consequently the electrical performance are not reduced. 


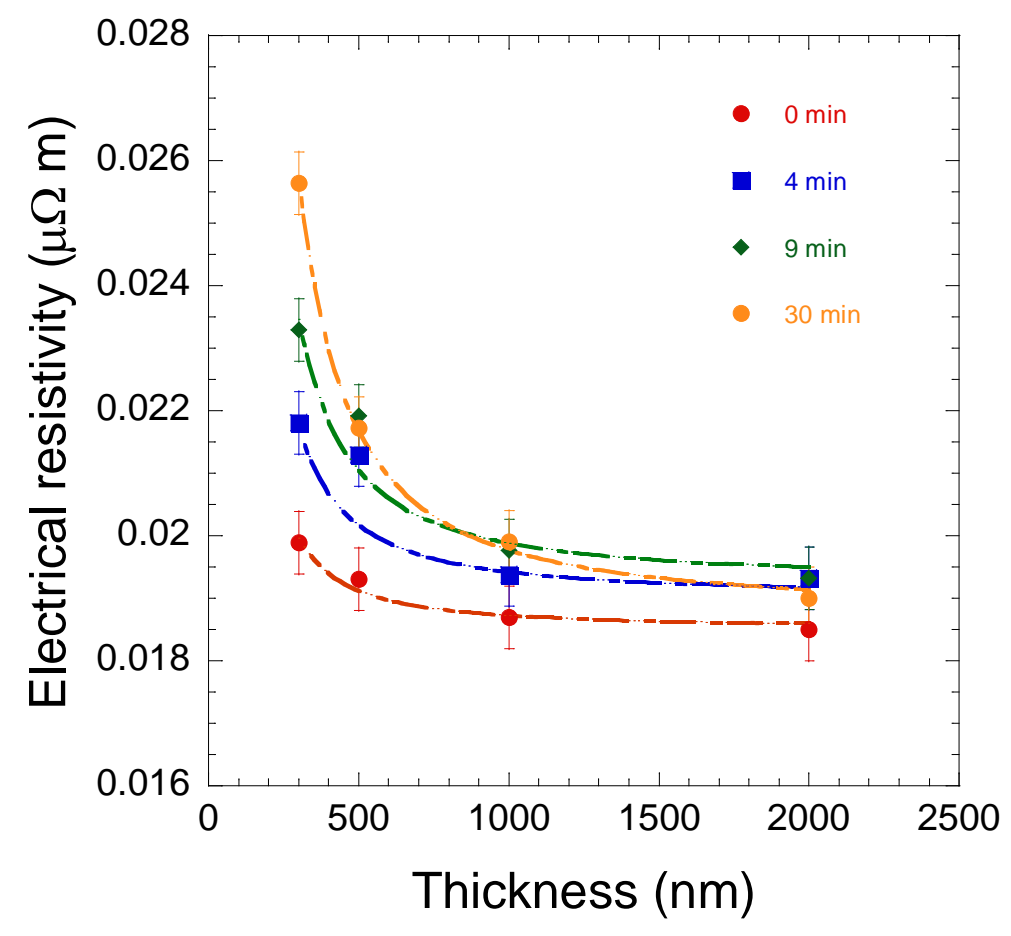

Figure 7: Electrical resistivity versus film thickness for different sulfurization times.

Another interesting test will be to study the influence of a flowing mixed gas environments on silver corrosion rates measured by resistivity techniques as shown in reference [20]. This study is planned for the future.

A marked increase of corrosion due to the porosity of electrodeposited coating is currently observed, when a very thin coating was used [21]. This is not the case for a layer prepared using PVD process which is less porous with a good grain joint quality.

Such porosity differences could explain the minimum thickness necessary to maintain good corrosion resistance (between 2 and $5 \mu \mathrm{m}$ for electrodeposited coatings against $1 \mu \mathrm{m}$ for films deposited using PVD process) .

Relating to our study and the differences observed for the coatings prepared under different sputtering conditions, SEM observations (figure 8) on silver coatings with thin (Ag6 $0.3 \mu \mathrm{m}$ ) and thick (Ag5 $2 \mu \mathrm{m}$ ) thicknesses have been realized at high magnifications (x10000). It reveals that the thin Ag film has small grain sizes, with a high grain boundary density and porosity. In contrast, except the nuggets dispersed at the surface, thick film shows large grain growth with low porosity and uniform coating. 


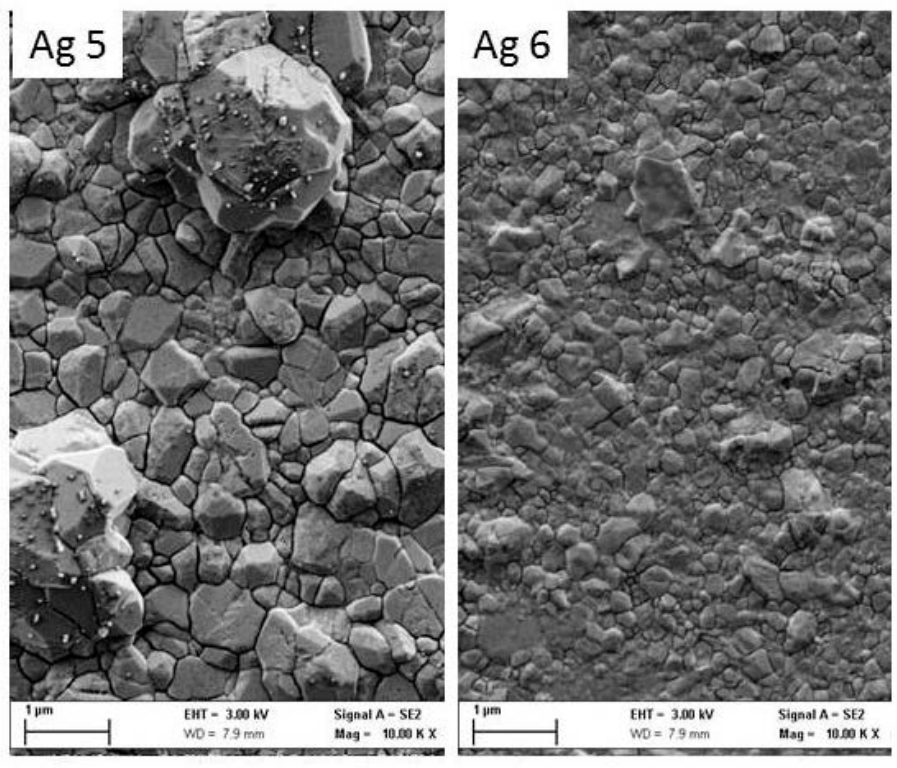

Figure 8 : SEM images of the Ag5 and Ag6 films at x10000 magnification.

\section{Conclusions}

We have studied the electrical properties of Ag films grown by PVD before and after corrosion experience. Before sulfurization, electrical properties of coatings are around 20\% higher than raw silver material.

Thinner silver layers $(0.3$ and $0.5 \mu \mathrm{m})$ have the highest increase of resistivity under sulfurization, as they are rapidly attacked by corrosive solution.

For $1 \mu \mathrm{m}$ of silver coating, samples realised at $8 \mu \mathrm{bar}$ get lower resistivity increase after 15 min sulfurization than $4.5 \mu$ bar. Our study shows that the minimum thickness of silver to resist to sulphurization atmosphere is one micron with an adherent coating behavior. The good corrosion resistance obtained in film of 1 micron in thickness is attributed to low porosity and uniform coating induced by the Physical Vapour Deposition process. The resistivity increased is a maximum of $10 \%$. After a sulfurization time of $600 \mathrm{~min}$, the electrical resistivity remains lower than $0.022 \mu \Omega$.m.

For industrial applications of silver coatings, these results are relevant. Coatings of 1 to $2 \mu \mathrm{m}$ of silver seem enough to resist to sulfurization and an electrical resistivity increase of $10 \%$ is observed. Usually, industrial electrochemical process result recommend to covered bars by 2 to $5 \mu \mathrm{m}$ of silver. Our results demonstrate that PVD process is as interesting and relevant as electrochemical ones, and we could decrease silver thickness on conductive electrical bars. 


\section{References}

[1] D. patent EP1788110 A1

[2] T.E. Graedel, J. Electrochem. Soc., 139 (1992) 1963.

[3] D. W. Rice, P. Peterson, E. B. Rigby, P. B. P. Phipps, R. J. Cappell, R. Tremoureux, J. Electrochem. Soc., 128 (1981) 275.

[4] C. J. Yang, C. H. Liang, X. Liu, Anti-Corrosion Methods and Materials, 54 (2007) 21.

[5] J. P. Franey, G. W. Kammlott, T. E. Graedel, Corrosion Science, 25, (1985) 133.

[6] M. Watanabe, A. Hokazono, T. Handa, T. Ichino, N. Kuwaki, Corrosion Science, 48 (2005) 3759.

[7] S. P. Sharma, J. Electrochem. Soc., 125 (1978) 2005.

[8] P. Vassiliou, C.T. Dervos, Anti-Corrosion Methods and Materials, 46 (1999) 85.

[9] L. Veleva, B. Valdez, G. Lopez, L. Vargas, J. Flores, Corrosion Engineering Science and Technology, 43 (2008) 149.

[10] E. Goli, H. Aghajani, Vacuum, 152 (2018) 231.

[11] P.J. Kelly, R.D. Arnell, Vacuum 56 (2000) 159.

[12] K .Shukla, R. Rane, J. Alphonsa, P. Maity, S. Mukherjee, Surface and Coatings Technology, 324, ( 2017) 167).

[13] M. Alishahi, F. Mahboubi, S. M. Mousavi Khoie, M. Aparicio, E. Lopez-Elvira, J. Méndez, R. Gago, RSC Adv., 6 (2016) 89061.

[14] Y. L. Chipatecua, J. J. Olaya, Diego F. Arias, Vacuum 86, ( 2012) 1393.

[15] F. Cemin, D. Lundin, D. Cammilleri, T. Maroutian, P. Lecoeur, and T. Minea J. Vac. Sci. Technol. A, 34 (2016) 051506.

[16] S. I. Sadovnikov, A. I. Gusev, A. A. Rempel, Phys. Chem. Chem. Phys., 17 (2015) 20495.

[17] C. Hillman, J. Arnold, S. Binfield, J. Seppi, DfR Solutions, College Park, MD, USA.

[18] S. Won Park, G. D. Han, H. Jong Choi, F B. Prinz, J. H Shim , Appl. Surf. Science 441 (2018) 718.

[19] C. Dias, M. P. Proenca, L. Fernandes, P. B. Tavares, R.Vilarinho, J. Agostinho Moreira, J. P. Araújo, J. Ventura, J. Nanosci. Nanotechnol. 16 (2016) 2608.

[20] B. S. Hindin, in Tri-Service Corrosion Conference, 2005.

[21] J. Song , L. Wang, A. Zibart, C. Koch, Metals 2 (2012) 450. 